\title{
LA ENSEÑANZA DEL DERECHO EN BACHILLERATO: DOCENTES Y LIBROS DE TEXTO EN EL INSTITUTO DE SEGUNDA ENSEÑANZA DE LOGROÑo
}

\author{
ISABEL MARTÍNEZ NAVAS \\ PROFESORA TITULAR DE HISTORIA DEL DERECHO Y DE LAS INSTITUCIONES \\ UNIVERSIDAD DE LA RIOJA \\ isabel.mnavas@unirioja.es
}

SUMARIO: I. INTRODUCCIÓN. II. LA MATERIA “DERECHO” EN LOS PLANES DE ESTUdiO DE ENSEÑANZA MEDIA EN ESPAÑA. III. LA ENSEÑANZA DEL DERECHO EN EL INSTITUTO DE SEgUNDA ENSEÑANZA DE LOGRoÑo. III.1. EL PROFESORADO. III.2. LOS MANUALES Y OTROS MATERIALES DOCENTES. III.3. APÉNDICE.

RESUMEN: La denominación, carácter y configuración de los estudios correspondientes a lo que hoy entendemos como enseñanza media, experimentaron numerosas transformaciones en los siglos XIX y XX. En este trabajo se presta atención a una de las materias incluidas en el currículo de estos estudios, de forma estable, en el primer tercio del siglo XX. Para ello, se toma como referencia su estudio en el Instituto de Segunda Enseñanza de Logroño en ese mismo período.

PalabraS ClAVE: enseñanza del Derecho, Manuales escolares, Instituto de Segunda Enseñanza, Enseñanza Secundaria.

\section{TEACHING OF LAW IN SECONDARY EdUCATION: TEACHERS AND TEXTBOOKS IN THE INSTITUTE OF SECONDARY EDUCATION IN LOGROÑO}

ABSTRACT: The designation, character and configuration of the studies corresponding to what we understand today as secondary education, underwent numerous transformations in the 19th and 20th centuries. The teaching of Law is a subject which was included in the curriculum for this entire period. This article explores how Law was taught at the Institute of Secondary Education in Logroño during the first third of the 20th century.

KEYWORDS: Teaching of Law, teaching materials, Institute of Secondary Education, Secondary Education.

\section{Introducción}

La inclusión de una materia sobre contenidos jurídicos en los planes de estudio de la enseñanza no universitaria experimentó numerosos vaivenes a lo largo del siglo XIX. Si la 
Constitución de 1812 proclamaba la obligación de explicar el propio texto constitucional en todas las Universidades y al propio tiempo la de incorporar a la enseñanza de las primeras letras-que se quería pública, universal, general y uniforme- una "breve exposición de las obligaciones civiles" que acompañaría al estudio del catecismo de la religión católica ${ }^{1}$, en relación a la denominada enseñanza secundaria -que es la que aquí interesa- será preciso aguardar casi hasta el final de la centuria para encontrar asentada en los planes de estudio una asignatura de cuya rúbrica se desprenda con claridad la finalidad de proporcionar a los estudiantes unas nociones acerca del Derecho español. Con todo, a los jóvenes no les resultaba por completo ajeno el Derecho, al que se acercaban en el marco de otras asignaturas del ámbito de las "Ciencias Morales", como la Filosofía, la Psicología y la Ética, que incorporaban nociones de Derecho natural.

Lo que pretendo en las siguientes páginas es tan sólo una primera aproximación a un tema que, sin duda, merecería un más amplio enfoque. Me limitaré, sin embargo, por ahora, a recordar brevemente el íter del sistema educativo español a lo largo del siglo XIX y el primer tercio del XX, a partir del que me interesará identificar la presencia o no de la materia "Derecho" en los diferentes planes de estudios alumbrados al compás del debate sobre la ordenación de la enseñanza secundaria. Seguidamente, centraré la atención en esas asignaturas impartidas en los Institutos de Enseñanza Secundaria. Concentraré el foco en uno de ellos, el actualmente denominado Instituto de Enseñanza Secundaria Práxedes Mateo Sagasta, ubicado en la capital de La Rioja. Y me acercaré a los responsables de esas asignaturas y a los materiales desarrollados para la docencia, a partir de los que podrán conocerse los contenidos y el enfoque personal del profesor de turno encargado de impartirlos. El período objeto de análisis es asimismo reducido. En este caso no por decisión propia, sino porque -como se verá después- será, en los últimos años del siglo XIX y hasta el inicio de la II República, cuando la enseñanza secundaria incorpore de forma regular una materia específicamente destinada al estudio del Derecho positivo español.

\section{La materia "derecho" en los planes de estudio de enseñanza media en España (1812-1934)}

La aprobación del Reglamento General de Instrucción Pública, en 1821, venía a dar satisfacción a la idea del constituyente gaditano al contemplar la inclusión de materias que incorporasen la formación política y ciudadana. La falta de aplicación en la práctica de este primer marco general, en el que se ordenaba el sistema educativo en tres niveles, daría paso, con el tiempo al desarrollo de planes y programas diferenciados para cada nivel educativo, hasta la promulgación del Real decreto de 4 de agosto de 1836, por el que se publicó el Plan General de Instrucción Pública, que, pese a su casi inexistente recorrido, sentará las bases de las principales leyes educativas españolas del siglo XIX².

\footnotetext{
${ }^{1}$ Sobre el estudio de lo que se dará en llamar "Derecho usual" en la primera enseñanza, MOLERO PINTADO, A., "El Derecho Usual en la escuela: antecedentes y controversias (1812-1900)", en El curriculum: Historia de una mediación social y cultural, IX Coloquio de Historia de la Educación, Granada, 23-26 de septiembre de 1996, Granada, 2 vols., Universidad de Granada, 1996, vol. I, pp. 131-137.

2 Para PUELLES, el fallido Plan del duque de Rivas, supuso en muchos extremos "un punto de no retorno", la introducción de modernidad e innovación en el sistema educativo de la mano del desarrollo de la enseñanza
} 
En lo que se refiere a la enseñanza secundaria, el primer paso relevante vendrá de la mano del conocido como Plan Pidal, de 1845, en el que se atendía tanto a la propia ordenación de las enseñanzas secundaria y superior -dividida la primera en dos niveles, elemental y de ampliación-, como a los contenidos curriculares de los diferentes grados y secciones en que se dividían -ciencias y letras, en el caso de la enseñanza secundaria de ampliación-, a los centros en que se impartían, al régimen jurídico del profesorado y, finalmente, a la propia Administración educativa ${ }^{3}$. Si detenemos la atención en la exposición que antecede a la parte dispositiva, destaca la clara opción por una enseñanza secundaria que se entiende a un tiempo como la destinada a proporcionar "los saberes indispensables en la sociedad a toda persona regularmente educada" ${ }^{4} \mathrm{y}$ asimismo a facilitar a quienes lo deseen el acceso a la enseñanza superior. Se piensa así en un currículo gradual, que de satisfacción a un tiempo a su doble naturaleza de enseñanza autónoma y preparatoria para la enseñanza superior. Por su parte, el art. $2^{\circ}$ del Real decreto de 17 de septiembre de 1845, no dejaba lugar a dudas acerca de la presencia en la enseñanza secundaria, en su grado superior, de una materia destinada a esa formación ciudadana, como era la denominada "Derecho político y administración". Sin embargo, el legislador no consideraba que esta formación debiese tener carácter universal, disponiendo que esta materia debía ser cursada únicamente por aquellos estudiantes que, habiendo concluido su formación secundaria elemental, decidiesen continuar sus estudios y optasen por la "sección de letras".

El plan de estudios de la enseñanza secundaria alumbrado en 1845 sería reformado, apenas dos años más tarde, dando al traste con los grados y secciones anteriormente señalados y sustituyéndolos por un nuevo plan, a cursar en cinco años, del que se caía la única asignatura cuya denominación evocaba indudables descriptores jurídicos. En su lugar, entraban en escena unos denominados "Elementos de Psicología, Ideología y Lógica", en los que se daría cabida a los rudimentos de educación ciudadana.

De menor alcance, la reforma de 1849 suprimió también esta última asignatura, que sería recuperada en 1850, ahora con la denominación de "Elementos de Psicología y Lógica", dejándose abierta la puerta a la inclusión de nuevas materias que incorporasen "otros conocimientos comunes a todas las Facultades y que deben formar parte de una educación general completa" ${ }^{5}$. Las siguientes y numerosas reformas del plan de estudios de la

secundaria. Por su parte, VIÑAO señala el período comprendido entre 1837 y 1845 como el de nacimiento de hecho de la educación secundaria en España. PUELLES BENÍTEZ, M., "Grandeza y miseria de los liberales españoles ante la educación secundaria”, en Historia de la Educación, 17 (1998), pp. 53-69; VIÑAO FRAGO, A., Política y educación en los orígenes de la España contemporánea. Examen especial de sus relaciones en la enseñanza secundaria, Madrid, Siglo XXI, 1982.

${ }^{3}$ El denominado Plan Pidal, en atención al nombre del entonces secretario del despacho de Gobernación, Pedro José Pidal, fue aprobado por Real decreto de 17 de septiembre de 1845 y publicado en la Gaceta de Madrid de 25 de septiembre.

${ }^{4}$ Con más bellas palabras -“los conocimientos útiles y agradables que constituyen la ilustración general de una nación civilizada" - se declaraba esa doble finalidad de la enseñanza secundaria en el Informe Quintana de 1813. QUINTANA, M.J., Obras completas, Madrid, Biblioteca de Autores Españoles, 1946, t. XIX, p. 180.

${ }^{5}$ El Real decreto de 28 de agosto de 1850, por el que se aprobaba la ordenación del sistema educativo y el plan de estudios de las diferentes clases de estudios, regulaba, en su art. 7, las materias que conformarían en adelante los estudios de segunda enseñanza, organizados en un único ciclo de cinco años, al que se accedía con diez años de edad, de conformidad con lo previsto en el art. 6. Por su parte, el art. 8 indicaba ligaba la posibilidad 
enseñanza secundaria incidirían sobre todo en la recuperación de los dos períodos o grados o de los seis años de duración, en tanto se mantenía la formación en "Elementos de psicológica, lógica y ética" ${ }^{6}$.

Será así el Gobierno provisional del Sexenio, el que, acuciado, en primer término, por la necesidad de ordenar el inicio inminente del curso en los diferentes niveles educativos, sentará, pocos días después, las bases de la nueva organización de la enseñanza secundaria que deberá sustituir a la que el proceso revolucionario había dejado atrás ${ }^{7}$. El carácter urgente y, por ende, limitado, de las medidas que se introducen, no empece, sin embargo, el importante calado de las mismas. De una parte, la decidida apuesta por la libertad de enseñanza y, de otro lado, la reforma que se considerará prioritaria de la segunda enseñanza ${ }^{8}$. Siguiendo para ello el ejemplo de otras naciones, se apuesta -a decir del ministro de Fomento, al que se habían atribuido las competencias en materia educativapor "una educación ilustrada, amplia, libre y con carácter práctico", base y "más sólido fundamento de la verdadera libertad". Para ello, resultaba imprescindible "variar la significación íntima, el espíritu y las tendencias de la segunda enseñanza". Esto es, dejar atrás su consideración propedéutica o de preparación para la enseñanza superior y dotarla de entidad propia:

Tiempo es ya -afirma con rotundidad el ministro Zorrilla9 ${ }^{9}$ de que la enseñanza pública satisfaga las necesidades de la vida moderna, y tenga por principal objeto no formar sólo latinos retóricos, sino ciudadanos ilustrados, que conozcan su patria en las diversas

de incrementar progresivamente el número de materias señaladas en el anterior, al perfeccionamiento de los métodos de enseñanza. Gaceta de Madrid, de 3 de septiembre de 1850.

6 Es en este período en el que se aprobará la Ley de Instrucción Pública de 1957. La conocida "Ley Moyano", de 9 de septiembre de 1857, estará vigente durante un largo período. Requirió de la adopción de medidas provisionales para su aplicación en el curso 1857-58, aprobadas por Real decreto de 23 de septiembre que, en su núm. 19, contemplaba la distribución de las materias que conformaban los estudios generales de segunda enseñanza, que deberían cursarse en seis años. Gaceta de Madrid, de 9 y de 24 de septiembre, respectivamente. Un breve recorrido por los cambios introducidos en estos años, en NEGRÍN FAJARDO, O., "Algunas características de la enseñanza secundaria española decimonónica a través de la legislación", en Historia de la Educación: Revista interuniversitaria, 2 (1983), pp. 275-286. Y para los efectos de estas páginas, resultan de gran utilidad la compilación realizada por UTANDE IGUALADA, M., Planes de Estudio de Enseñanza Media, Madrid, Ministerio de Educación Nacional, 1964, si bien el autor no reproduce en su integridad los textos transcritos, limitándose a aquellos aspectos que inciden en la ordenación de los estudios de enseñanza secundaria.

7 Un Decreto de 21 de octubre de 1868 hubo de acometer las reformas imprescindibles para hacer posible el inicio del curso escolar, afectado sobre todo en lo tocante a algunos estudios universitarios. Por lo que se refiere a la enseñanza secundaria, se estimó necesario tan sólo apuntar en ese momento la fecha de inicio del curso en los Institutos, Gaceta de Madrid, de 22 de octubre.

${ }^{8}$ Se apostó decididamente por la libertad de enseñanza, negándose el monopolio del Estado en la educación, tal como se plasmó después en la Constitución de 1869. De este modo, se suprimieron las trabas administrativas impuestas a los centros educativos. Por otra parte, la libertad de enseñanza preconizada en 1868 se extendía, claro está, como después veremos, a la facultad de los profesores para elegir libremente los programas y libros de texto que utilizarían en sus clases. Un breve repaso a la evolución del derecho a la educación y la libertad de enseñanza en nuestra historia constitucional en MARTÍNEZ NAVAS, I. y MÚÑOZ ARNAU, J.A., "Historia de la Educación”, en GONZÁLEZ MENORCA, L. y NAVARIDAS NALDA, F. (coords.), Acción pedagógica en los centros escolares: enfoque teórico y práctico, Logroño, Fundación Universidad de La Rioja, 2014, pp. 29-42.

${ }^{9}$ Por Decreto de 25 de octubre de 1868 se adoptaban nuevas medidas en relación a la enseñanza secundaria, que se entendían igualmente provisionales, a la espera de que las Cortes diesen a la luz una nueva Ley de Instrucción Pública. Gaceta de Madrid, de 26 de octubre. 
manifestaciones de la vida nacional, y puedan enaltecerla y honrarla aplicando ingeniosa y libremente su actividad intelectual al progreso científico, artístico y literario.

El joven que seguía antes la segunda enseñanza y recibía el grado de Bachiller en Artes, no tenía idea alguna de la legislación de su país, ni de su organización política o social, ni de los elementos de riqueza que posee, ni mucho menos de aquellos estudios artísticos, tan importantes como amenos, que distinguen a los pueblos civilizados y forman principalmente en carácter de las Naciones cultas, suavizando las costumbres, influyendo poderosamente en la moralidad y proporcionando gratas ocupaciones, como descanso de áridas tareas y consuelo de dolorosos contratiempos.

El nuevo plan de estudios incorporaba unos "Principios de Derecho y nociones de Derecho civil español" y unas "Nociones elementales de Derecho español políticoadministrativo y penal", que podrían cursarse junto a las materias que conformaban los estudios generales de segunda enseñanza ${ }^{10}$.

El último tercio del siglo XIX contemplará, como no, numerosos -aunque no tan nuevos- cambios en la ordenación de la segunda enseñanza y en los planes de estudio ${ }^{11}$. De todos esos currículos ${ }^{12}$-excepción hecha del plan de estudios aprobado en 189913- formará parte ya una o varias asignaturas cuyo contenido jurídico aparecía con rotundidad en sus rúbricas: "Principios de Derecho natural y Nociones del civil y mercantil español”, "Nociones de Derecho político, penal y procesal español”, “Economía política y Legislación mercantil e industrial", "Ética y Derecho usual con Economía Política", y, las que terminarían por imponerse en la transición al siglo XX: "Derecho usual" y "Rudimentos de Derecho"14. Junto a éstas, otras como "Sociología y Ciencias éticas", "Filosofía”, "Psicología, Lógica y Ética", "Economía política" o "Doctrina cristiana", conformaban, junto a las materias propiamente jurídicas el ámbito de las llamadas "Ciencias morales", estableciéndose un orden de

10 Ibídem, arts. 1ㅇa 7ㅇ․

11 Como recuerda GÓMEZ GARCÍA, resultaron especialmente problemáticas la conceptualización y la nomenclatura, pero también los contenidos, de manera que los diferentes planes de estudios "fueron variando al compás de las distintas concepciones que desde la teoría educativa o desde el discurso político enmarcaban este nivel de conocimientos", GÓMEZ GARCIA, N., "Introducción a la Historia de la Educación Secundaria", en Historia de la Educación, 17 (1998), pp. 9.10.

12 La materia jurídica estará presente en el plan de estudios de 1894, debiendo enseñarse en el cuarto y último curso de la formación generalista. Su contenido era definido en los siguientes términos: “debe estar constituido por un programa de lo más característico y fácilmente asequible al vulgar conocimiento acerca de las instituciones más salientes y de mayor práctica en el Derecho público y privado". Real decreto de 15 de septiembre de 1894, reorganizando los estudios de segunda enseñanza. Gaceta de Madrid, de 18 de septiembre.

13 “Desaparecen por la reforma propuesta -señalará la exposición de motivos- del plan de segunda enseñanza el Derecho usual, la Economía política y la Contabilidad, que, si respondían a la tendencia de dar carácter enciclopédico a la segunda enseñanza, no parece que tengan en ella lugar adecuado", Real decreto de 26 de mayo de 1899, reorganizando los estudios se segunda enseñanza, en Gaceta de Madrid, de 30 de mayo. Y, en efecto, las llamadas "Ciencias Morales" se restringen en ese momento a la "Religión" y "Elementos de Filosofía", siendo en esta última en la que tendrían cabida los conocimientos correspondientes a "Derecho natural".

${ }^{14}$ Aquí referencia a todas ellas. 
prelación que determinaba la posibilidad de acceder al examen de las diferentes asignaturas ${ }^{15}$.

Sobre su innegable relevancia para la formación de los jóvenes y la falta de necesidad de justificar su inclusión, apuntaba, el ministro de Fomento, en 1898:

El Derecho usual comprende aquellas nociones del público que ningún ciudadano debe ignorar si ha de ejercitar conscientemente sus derechos y estar informado de sus sociales y políticos deberes, y aquellas otras doctrinas de cuotidiana aplicación en la vida, como el derecho de familia, el de propiedad y el de sucesiones y contratos. Y si la necesidad de atender a este olvidado e importantísimo aspecto de la cultura humana no fuese suficiente para recomendar el restablecimiento de esta asignatura, incluida en el plan de 1894, bastaría a imponerlo desde luego el aplauso con que fue recibida por la opinión y el dolor con que recientemente lamentaron su desaparición las Cortes españolas ${ }^{16}$.

El nuevo siglo arrancaría con la novedad del establecimiento del Ministerio de Instrucción Pública y Bellas Artes y -en lo que aquí interesa- con la asignatura "Derecho usual" presente de nuevo en el último curso de los estudios de la segunda enseñanza ${ }^{17}$. Poco después, a la espera de una nueva Ley de Instrucción Pública, fueron introduciéndose las modificaciones legislativas necesarias para garantizar el desarrollo ordinario de la actividad académica, que modificaron, una vez más, los planes de estudio y que vinieron, a la postre, a dotar de nueva ordenación al sistema educativo español. Que era necesaria la formación de una nueva Ley que sustituyera a la Ley Moyano de 1857 y solventase de manera decisiva los problemas derivados de los diferentes modelos que habían venido enfrentándose "luchan los principios antiguos con los nuevos, pugnan por rechazarse mutuamente, y de tal manera es difícil discernir cuáles medidas acarrearán beneficios, y cuáles sólo servirán para añadir nuevos trastornos y ocasionar evidentes daños a nuestra enseñanza"- resultaba claro para el entonces ministro de Instrucción Pública, conde de Romanones ${ }^{18}$. Pero la nueva Ley no llegará tampoco en este momento y así, a pesar del juicio negativo que para el ministro merecía la inveterada práctica de "legislar desde la Gaceta", en abril de 1901, se regularon los exámenes, tanto de ingreso, como los relativos a las diferentes materias, composición de los tribunales de examen, etc. ${ }^{19}$. Cuatro meses más tarde, veía la luz un nuevo plan de estudios como resultado de lo que, desde el Ministerio, se consideraban "algunas correcciones, aunque interesantes, de poca importancia", al tiempo que se reordenaban las enseñanzas y los centros en los que éstas se impartían, el número de alumnos por clase, los órganos de gobierno de los que pasaban a denominarse Institutos

\footnotetext{
15 Psicología y lógica, precedía a Ética, a Derecho usual y a Economía en el plan de estudios de 1898. Real decreto de 13 de septiembre de 1898, en Gaceta de Madrid, de 14 de septiembre.

16 Ibídem, Exposición a cargo del entonces ministro de Fomento, Germán Gamazo.

17 Real decreto de 19 de julio de 1900, reformando el plan de estudios de segunda enseñanza, Gaceta de Madrid, de 22 de julio.

18 Real decreto de 12 de abril de 1901, relativo a reformas en la enseñanza oficial, Gaceta de Madrid, de 14 de abril.

19 Ibídem.
} 
Generales y Técnicos, la plantilla de los mismos, o la inspección a cargo de la Administración educativa ${ }^{20}$.

Hubiera deseado el Ministro que suscribe -señalaba en agosto de 1901- hacer algunas modificaciones importantes en el plan de estudios del grado de Bachiller; pero le ha detenido, sobre todo, una razón, y es que resultaría trastornador y hasta poco serio, que tres Ministros que se han seguido en el departamento de Instrucción pública hubieran sometido a la aprobación de V.M. tres distintos planes de segunda enseñanza.

Las modificaciones "de poca importancia" introducidas en el plan de estudio alcanzaron, de hecho, a la asignatura "Derecho usual", que fue sustituida por "Ética y rudimentos de Derecho" y que continuó impartiéndose en el último curso del grado de Bachiller ${ }^{21 .}$

En 1926, el conocido como Plan Callejo -impulsado por el ministro de Instrucción Pública y Bellas Artes, Eduardo Callejo de la Cuesta- recuperó los dos grados, con sus diferentes orientaciones, dentro del Bachillerato:

\begin{abstract}
Más el Bachillerato, que por un lado es complemento de la instrucción primaria y por el otro forma la inteligencia para estudios superiores, no es una mera preparación para los estudios de Facultad, sino que en muchos casos tiene y debe tener sustantividad propia para aquellos que no han de proseguir nuevos estudios; para los que se encaminan a Escuelas especiales: civiles, militares y navales; para las profesiones no universitarias; para muchos funcionarios del Estado; para gran número de las señoritas que asisten a los Institutos; para todos, en fin, los que, sin aspirar a ingresar en las Universidades deseen mejorar la cultura que en la Primera enseñanza obtuvieron ${ }^{22}$.
\end{abstract}

En ese nuevo marco, la asignatura, que pasaba a denominarse "Deberes éticos y cívicos y Rudimentos de Derecho", formaba parte del currículo del Bachillerato elemental, impartiéndose en el tercer y último curso ${ }^{23}$.

Derogado en 1931, un Decreto de 7 de agosto dispuso el restablecimiento, "para que rija únicamente durante el curso de 1931 a 1932", del plan de estudios de Bachillerato del año 1903, con las adaptaciones que se estimaron necesarias. De este modo, la asignatura

\footnotetext{
${ }^{20}$ Real decreto de 17 de agosto de 1901, reformando los estudios de segunda enseñanza y las enseñanzas técnicas del Magisterio, Agricultura, Industria, Comercio, Bellas Artes y Artes Industriales, Gaceta de Madrid, de 19 de agosto.

${ }^{21}$ Conservó idéntica denominación en la reforma curricular introducida dos años más tarde, siendo ministro de Instrucción Pública Gabino Bugallal, por Real decreto de 2 de septiembre de 1903, Gaceta de Madrid, de 16 de septiembre.

22 Real decreto de 24 de agosto de 1926, relativo al nuevo plan del Bachillerato, Gaceta de Madrid, de 28 de agosto.

23 Ibídem, art. 4ํ: "Los estudios exigidos para el Bachillerato elemental y su distribución en cursos será el que determina el plan siguiente: [...] Tercer año: Geografía e Historia de España; Historia natural; Filología e Higiene; Deberes éticos y cívicos y rudimentos de Derecho; Francés (tercer curso)”.
} 
"Ética y Rudimentos de Derecho" volvía a formar parte de las cursadas por los estudiantes de la Sección de Letras, en el sexto curso del grado ${ }^{24}$.

\section{La enseñanza de Derecho en el Instituto de Segunda Enseñanza de Logroño}

Las primeras noticias relativas al entonces denominado "Instituto Riojano", puesto en marcha con el auspicio de la Diputación provincial de Logroño y el Ayuntamiento de la ciudad, corresponden al año 1839, en que habría iniciado su actividad una nueva institución educativa en la capital riojana en la que se impartirían la enseñanza elemental, la secundaria y algunas asignaturas complementarias como Música o Agricultura25. El centro, que contó, en su primer año, con una matrícula cercana al centenar y medio de alumnos, dio paso, poco después, al Instituto de Segunda Enseñanza de Logroño ${ }^{26}$.

En efecto, la creación del Instituto de Segunda Enseñanza de Logroño se habría resuelto en el mes de octubre de $1842^{27}$, iniciando su actividad en el mes siguiente y ocupando en los cincuenta años siguientes diferentes sedes hasta llegar a quedar definitivamente instalado en el edificio construido con tal fin, en el curso 1900-0128.

Es en este tiempo también cuando -como antes recordé- las asignaturas "Derecho usual" o "Rudimentos de Derecho" habían sido definitivamente introducidas en el currículo de los estudiantes de Bachillerato, manteniéndose en el mismo hasta la finalización del curso 1932-33.

24 Decreto de 7 de agosto de 1931, poniendo en vigor, durante el tiempo que comprende el curso académico 1931 a 1932, el plan de estudios del Bachillerato del año 1903, adaptado para los alumnos del mencionado curso 1931-1932, Gaceta de Madrid, de 8 de agosto.

25 RAMÍREZ OCHAGAVÍA, F., Instituto Sagasta de Logroño. 25 años de Historia (1843-1868), Logroño, 2001, pp. 21-22.

26 Para RAMÍREZ OCHAGAVÍA parece probable que el Instituto Riojano interrumpiese su actividad académica al finalizar el curso 1939-40, Instituto Sagasta..., cit., pp. 23-24. Por su parte, F. BLANCO MARTÍN, quien durante los últimos años ha sido bibliotecario del Instituto de Enseñanza Secundaria" Práxedes Mateo Sagasta" de Logroño y conoce bien el fondo documental del archivo del Instituto -disperso entre los de la propia institución, el Archivo Histórico Provincial de La Rioja, al que se transfirió el catalogado como "Fondo Sagasta", o el Instituto de Estudios Riojanos-, apunta la hipótesis de la continuidad de la actividad académica. Sus apuntes han ido engrosando progresivamente la información que, acera de la historia del Instituto, ha podido reconstruir sobre la base de la documentación original y que ha puesto a disposición de todos a través del sitio web del propio Instituto.

${ }^{27}$ La Gaceta de Madrid, del 31 de octubre de 1842, publicaba la Orden de la Regencia por la que se creaba un Instituto de Segunda Enseñanza en Logroño y se disponía la constitución inmediata de una Junta de Instalación, que debía presidir el jefe político de la Provincia y de la que formarían parte un representante de la Diputación provincial, otro del Ayuntamiento de Logroño y dos vocales más, elegidos por el jefe político, de entre personas de reconocido prestigio.

28 Sobre sus anteriores ubicaciones y el proyecto de construcción del edificio ubicado en el centro de la ciudad, CERRILlo RUBIO, I., "Los inicios de la arquitectura escolar en Logroño: el Instituto de Segunda Enseñanza y la Escuela de Artes y Oficios", en MARTÍNEZ EZQUÉRRO, A. y MARTÍNEZ NAVAS, I., La educación en el valle del Ebro: estudios históricos y filológicos, Logroño, Instituto de Estudios Riojanos, 2014, pp. 139-158 y "La arquitectura escolar en La Rioja en el siglo XIX: del academicismo al historicismo”, en Berceo, 165 (2013), pp. 27-62. 


\title{
III.1. El profesorado
}

El comienzo del siglo XX vino acompañado -como antes se vio- de importantes novedades en materia de educación. Al flamante nuevo Ministerio de Instrucción Pública y Bellas Artes se atribuían las competencias en materia educativa hasta entonces vinculadas a otros Departamentos y el segundo de los ministros a su frente, Álvaro de Figueroa y Torres, conde de Romanones, ambicionaba la creación de su propia Ley de educación nacional.

Desde el año 1857 no se han discutido ante éstas -dirá en referencia a las Cortes- de una manera cumplida y radical los más vitales problemas de la enseñanza, y ya no cabe dilatar por más tiempo esa discusión, en la que las opiniones y los sentimientos del país han de manifestarse con claridad ${ }^{29}$.

Los problemas de la enseñanza, que apuntaba el ministro, eran, por lo que se refiere al profesorado, la cortedad de sus retribuciones -significativamente las del profesorado auxiliar-, la existencia de incompatibilidades para la formación de los tribunales examinados y la complejidad de una plantilla aún por definir. A todos estos extremos trató de dar solución el Gobierno en 1901. En primer término, entendiendo imprescindible que se retribuyese "decorosamente" al profesorado auxiliar de los Institutos, evitando así que se viesen abocados a prestar simultáneamente sus servicios en centros educativos particulares, lo que dificultaba la formación después de los tribunales de examen ${ }^{30}$. En atención a ésta y otras dificultades, que podían observarse en el día a día de los centros, un Real decreto de 16 de agosto de 1901 apostó por la que se pretendía una reorganización general de los Institutos Generales y Técnicos, siendo conscientes de la complejidad de obtener una acogida satisfactoria por parte del profesorado ${ }^{31}$ :

\begin{abstract}
El arduo problema de la educación nacional no puede ser resuelto con reformas parciales insistirá el conde de Romanes-; en determinados órdenes de la enseñanza se requiere un cambio rápido y radical de los Centros que sirven de órgano adecuado al ejercicio de las funciones docentes, y la experiencia ha demostrado por modo claro y evidente que se impone este cambio. No llega el Ministro que suscribe a suponer con optimismo fuera de realidad que esta transformación pueda realizarse en plazo breve, y mucho menos que sus beneficiosos resultados se evidencien desde el primer momento; porque si bien es fácil decretar la sustitución de unos planes de enseñanza por otros planes, es empresa difícil, que requiere la cooperación de todos, y que exige para su desenvolvimiento un plazo nada breve, la de poner al personal docente en condiciones de responder a la misión que le está encomendada.
\end{abstract}

\footnotetext{
${ }^{29}$ Real decreto de 12 de abril de 1901, relativo a reformas en la enseñanza oficial, cit.

30 Se ordenaron los diferentes exámenes -de ingreso, de asignaturas, de reválida y grados-, así como las calificaciones de los exámenes y la composición de los Tribunales de examen, ibídem.

31 Real decreto de 16 de agosto de 1901, organizando los Institutos Generales y Técnicos, publicado inicialmente en la Gaceta de Madrid de 19 de agosto de 1901, habiéndose advertido algunos errores de copia en el texto, se publicó una nota de rectificación y el texto íntegro del Real decreto en la Gaceta de 25 de agosto de 1901.
} 
Conscientes, asimismo, de la escasez de recursos con los que hacer frente a una reforma que podría haber sido más ambiciosa ${ }^{32}$, la nueva organización habría incidido en la reorganización de los Institutos de Segunda Enseñanza, que, con la nueva denominación de Institutos Generales y Técnicos, daban cabida a las enseñanzas de Bachillerato y junto a éstas a los estudios elementales y superiores de Magisterio, a los estudios elementales de Agricultura, Industria, Comercio y Bellas Artes y asimismo a enseñanzas nocturnas para obreros.

En su capítulo segundo, dedicado a los estudios de Bachillerato se incluyeron, junto a las previsiones relativas a estas enseñanzas, las que tenían que ver con el profesorado o la nueva configuración de los Claustros docentes, a los que quedaban incorporados los profesores de los restantes estudios impartidos en el Centro ${ }^{33}$. Por lo que se refiere a la plantilla de personal de los Institutos, junto a los destinados específicamente a atender a los estudios de Magisterio y de carácter técnico, se preveía la existencia de doce catedráticos, tres profesores, cuatro auxiliares -el propio Real decreto disponía la creación de un cuerpo de auxiliares de Institutos- y un capellán. Uno de los doce catedráticos lo sería de "Psicología, Lógica y Ética y rudimentos de Derecho".

El curso 1901-02 se inauguraría así en el Instituto General y Técnico de Logroño, en su nueva seda, bajo la dirección de Antonio Jimeno Caridad, que a la sazón ocupaba la Cátedra de Psicología, Lógica, Ética y Rudimentos de Derecho desde hacía tres años. El expediente personal de Jimeno Caridad permite conocer algunos datos de carácter personal y fundamentalmente los relativos a su formación previa y desarrollo profesional ${ }^{34}$. Natural de Zamora, recaló en Logroño cuando, a la edad de treinta años, obtuvo, por oposición, la condición de catedrático de Psicología, Lógica y Filosofía Moral del Instituto de la capital riojana ${ }^{35}$. Jimeno se habría licenciado años atrás en Filosofía y Letras en la Universidad de Salamanca. Concursó poco después a oposiciones a Cátedra de diversas especialidades y para diferentes destinos: de Retórica y Poética, de Latín y Castellano y, como ya he apuntado, de Psicología, Lógica y Filosofía Moral. Hasta la obtención de ésta última, residió en Zamora, donde enseñó Filosofía en el Colegio de Segunda Enseñanza Santo Tomás de Aquino. En 1896 fundó El Heraldo de Zamora, que dirigió hasta su traslado a Logroño. Instalado ya en

32 "Ofrece desde luego obstáculo infranqueable al necesario desenvolvimiento de todo proyecto reformista de la enseñanza, la penuria de nuestro Tesoro, que no consiente, lo menos por ahora, gravamen alguno en el presupuesto consagrado a la instrucción pública. Claro está -se lamenta Romanones- que la exigüidad de las cifras de este presupuesto está en proporción con la inferioridad de nuestra cultura respecto a la de otros pueblos de Europa, y que el aumento exigible no podrá demorarse largo tiempo si hemos de rehabilitarnos como nación progresiva, y si no hemos de quedarnos completamente distanciados de todo lo que significa y representa el verdadero sentido de la civilización". Esta es la razón dirá por la que se resuelve la reunión en unos mismos centros de las recién creadas enseñanzas técnicas y lo es también para incluir junta a éstas las enseñanzas de Magisterio, ibídem.

33 Ibídem, art. 15.

34 Archivo Histórico Provincial de La Rioja [en adelante, AHPLR], Fondo Sagasta, núm. 567.

35 En el expediente se conserva un traslado de la Real orden de 8 de junio de 1898, de nombramiento de Antonio Alejandro Ángel Julio Alfonso Jimeno Caridad como catedrático numerario de Psicología, Lógica y Filosofía Moral. Consta asimismo certificación de su toma de posesión, el 29 de junio, previa autorización por la Dirección General de Instrucción Pública, ibídem. 
el Instituto riojano, se ocupó de su Biblioteca y, en 1900, fue nombrado director, cargo que desempeñará hasta su fallecimiento en $1906^{36}$.

Tras la muerte de Antonio Jimeno Caridad, se sucedieron al frente de la cátedra de Psicología, Lógica y Rudimentos de Derecho del Instituto de Logroño los profesores Julio del Riego y Campos, Rafael Serrano Arroyo, Francisco Valderrábano y Morán y Federico Dalmau Gratacós. De sus expedientes personales, se desprende su participación, en algún caso, el fallecimiento en activo y, en los restantes, la participación en concursos de traslado, que les llevaron a permanecer, en general, en la capital riojana, poco tiempo ${ }^{37}$.

El último de los encargados de impartir la asignatura "Rudimentos de Derecho" fue Calixto Terés Garrido, natural de Logroño, sacerdote, se licenció en Filosofía y Letras en la Universidad de Zaragoza en 1897. Durante algunos años fue profesor del Seminario Conciliar de Logroño y asimismo impartió enseñanzas de Bachillerato en alguna institución privada en la capital riojana ${ }^{38}$. En 1912 era nombrado catedrático numerario de Psicología, Lógica, Ética y Rudimentos de Derecho del Instituto General y Técnico de Logroño, al haber permutado la plaza que venía desempeñando en Gerona con quien venía desempeñándola en Logroño ${ }^{39}$. Como el primero de los catedráticos mencionados, asumió también durante algún tiempo la Dirección del Instituto. En su caso fue a partir de 1939, manteniéndose en el cargo hasta el año $1945^{40}$. De Calixto Terés se hizo notar, a su llegada al Instituto logroñés, en 1912, que era persona bien conocida en la ciudad, no sólo por su excelente disposición al estudio, sino porque "desde los albores de la adolescencia, mientras hubo ocasiones para tanto, consagró al catequismo libre y espontáneamente, con altas miras y espíritu cristiano y pedagógico, las horas que las obligaciones escolares le dejaban libre de otro trabajo" 41. Una percepción bien distinta de la actuación de Terés, en este caso referida al período correspondiente a la Guerra civil y hasta su fallecimiento en 1945, es la que se refiere a su papel como jefe provincial de prensa de Logroño y su no inicua intervención cuando se

\footnotetext{
36 Una aproximación a su trayectoria profesional y a algunas de sus obras, en FERNÁNDEZ LÓPEZ, J., "Antonio Jimeno Caridad, director del Instituto Provincial de Logroño y traductor de Horacio”, en La educación en el valle del Ebro, cit., pp. 213-224.

37 Los expedientes en AHPLR, Fondo Sagasta, núms. 573, 574, 575 y 564, respectivamente.

38 BUJANDA, F., Historia del viejo Seminario de Logroño, Logroño, Instituto de Estudios Riojanos, 1948, p. 160.

39 La permuta se les autorizó por Real orden de 27 de julio de 1912, según consta en los respectivos expedientes personales, AHPLR, Fondo Sagasta, 564 y s/núm.

40 Su expediente personal en, ibídem, s/núm. Según consta en el mismo, en 1945 cesó en el Instituto, al haber alcanzado la edad de jubilación. Su relación personal con José María Escrivá de Balaguer comenzaría probablemente en el Instituto de Logroño, en el que fue su profesor de la asignatura Ética y Rudimentos de Derecho, que se impartía en sexto curso de Bachillerato, en el curso 1917-18 y en la que el joven estudiante obtuvo la calificación de "sobresaliente con premio". Posteriormente, formaría parte del círculo de sacerdotes amigos del fundador del Opus Dei. TOLDRÁ PARÉS, J., "Los estudios de Josemaría Escrivá en Logroño (19151920), en Anuario de Historia de la Iglesia, vol. VI, núm. 1 (1997), pp. 607-674; GONZÁLEZ GULLÓN, J.L. y AURELL, J., "Josemaría Escrivá de Balaguer en los años treinta: los sacerdotes amigos”, en Studia et Documenta: rivista dell'Istituto Storico San Josemaría Escrivá, 3 (2009), pp. 41-106.
}

41 Memoria acerca del estado del Instituto General y Técnico de Logroño durante el curso de 1911 a 1912, leída en la apertura del de 1912 a 1913 por D. Roque Cillero y Plágaro, Secretario de dicho centro, Logroño, Librería Moderna, 1912, pp. 6-7. 
trataba de poner de manifiesto la indubitable fidelidad al Régimen, o de manifestar dudas acerca de tal adhesión ${ }^{42}$.

III.2. Los manuales y otros materiales docentes.

La utilidad de los libros de texto resultaba indudable en la enseñanza secundaria. Y no únicamente en relación a aquellos estudiantes que, por no asistir a clase, precisaban de la seguridad que representaba contar con un manual que les permitiese preparar el examen al que concurrían como "alumnos libres". También lo era para el resto del alumnado, al constituir -en palabras del ministro riojano Manuel Orovio- una guía para seguir las explicaciones del profesor, la necesaria ampliación del programa de la asignatura y la garantía de que la enseñanza se adecúa a los adelantos de la ciencia ${ }^{43}$. No era fácil, sin embargo, contar con libros de texto de las diferentes materias y tampoco garantizar la calidad de los mismos. Los sucesivos Gobiernos adoptaron diferentes medidas tendentes a resolver esa dificultad: control de los textos, dotación de premios o repercusión directa en las oposiciones de ascenso a los autores de libros de texto, elaboración de listas que evitasen la imposición del texto único, etc. ${ }^{44}$.

El problema de la escasez dio paso, con el tiempo, a una nueva polémica que tenía que ver justamente con lo contrario ${ }^{45}$. Como ha explicado Canes Garrido, en el último tercio del siglo XIX se pasó de la escasez a la abundancia de libros de texto. El Gobierno debía ahora enfrentar un problema -el de la existencia de un gran número de libros de texto correspondientes a las diferentes materias impartidas en la enseñanza secundaria- que estribaba, en realidad, en la capacidad por parte de los profesores de "imponer" a sus estudiantes la utilización de los textos que recomendaban y de los que, en muchas ocasiones, resultaban ser autores ${ }^{46}$.

42 Sobre sus informes favorables para el ejercicio del periodismo, SALAS FRANCO, M.P., "Periodistas para después de una Guerra. La plantilla de Nueva Rioja en sus primeros años de andadura (1938-1943)", en Berceo, 159 (2010), pp. 205-276.

43 Exposición del Real decreto de 26 de febrero de 1875, derogando los artículos 16 y 17 del Decreto de 21 de octubre de 1868, y disponiendo vuelvan a regir respecto de textos y programas las prescripciones de la Ley de 9 de setiembre de 1857 y del reglamento general de 20 de julio de 1859, publicado en la Gaceta de Madrid, de 27 de febrero.

44 Sobre la problemática de los libros de texto, CANES GARRIDO, F., "El debate sobre los libros de texto en Secundaria en España (1875-1931), en Revista Complutense de Educación, vol. 12, núm. 1 (2001), pp. 357-395.

45 Sobre un debate al respecto en las Cortes, en los años sesenta del siglo XIX, ARAQUE, N. y RODRÍGUEZ, C., “Cien años de enseñanza de la Filosofía en el Instituto Cardenal Cisneros de Madrid (1837-1936)", en Revista Complutense de Educación, vol. 22, núm. 1 (2011), p. 58.

46 Un estudio sobre los manuales utilizados en los Institutos gallegos revela que, a finales del siglo XIX, la práctica habitual consistía en la utilización de manuales elaborados por los propios profesores de la materia, "siendo bastante común que el profesorado de estos centros recomiende su propio manual, o señale un material alternativo, de factura también personal, como es lo que a modo de apuntes de clase se llaman "Lecciones del profesor"”, BENSO CALVO, C. y RIVAS BARRÓS, I., "Los manuales utilizados en los Institutos gallegos en la segunda mitad del siglo XIX”, en GÓMEZ GARCÍA, M.N. y TRIGUEROS GORDILLO, G., Los manuales de texto en la enseñanza secundaria (1812-1990), Sevilla, ed. Kronos, 2000, p. 201. 
La preocupación ante la proliferación de manuales o libros de texto, queda patente en las siguientes líneas -de un Informe bien conocido- dirigidas, en 1898, por el director general de Instrucción Pública, Eduardo Vicenti, al ministro de Fomento ${ }^{47}$ :

[...] siente el ánimo asombro al observar el crecido número de obras que hay señaladas de texto, la extensión desmedida de la mayor parte y el precio considerable de muchas de ellas, deduciéndose también [...] la gran variedad que se observa en el concepto y límites con que en buen número de casos es entendida y explicada la misma asignatura.

Como señala al comienzo de su exposición, había sido el clima generado en lo que hoy denominaríamos la clase política, la opinión pública y publicada y la propia Academia ${ }^{48}$, lo que les había decidido a llevar a cabo un estudio estadístico que les permitiese conocer cuántos eran los libros de texto recomendados y utilizados en las instituciones educativas en España. Los resultados -a decir de autor- evidenciaban el por qué venía llamándose la atención del Gobierno desde diferentes instancias y por qué era preciso adoptar decisiones al respecto.

En un corto espacio de tiempo se habrían impulsado diferentes medidas tendentes a hacer frente al problema: Circulares dirigidas a los responsables de las Universidades e Institutos del Reino solicitando información sobre los libros de textos que se utilizaban en sus centros. Solicitud de informe al Consejo de Instrucción Pública acerca de la posibilidad de establecer un programa único y resolver sobre la aprobación de los libros de texto. Disposiciones prohibiendo la venta de libros de texto dentro de los establecimientos de enseñanza o encomendando al mencionado Consejo la formación de un cuestionario general sobre libros de texto ${ }^{49}$.

La cuestión más delicada de entre las apuntadas era la que chocaba con la libertad de cátedra. Ciertamente podía limitarse el precio, podían establecerse filtros que permitiesen velar por la calidad de los textos, e incluso podían señalarse los marcos de cada asignatura -su carácter, extensión, fines, o presencia en los cuadros de enseñanza-, pero todo ello debía hacerse sin menoscabo del libre criterio del profesor en el ejercicio de la actividad académica. El problema no se resolvía, pues, con la formación de Cuestionarios generales, con ser estos relevantes para atajar otra de las cuestiones sobre las que versaban habitualmente las quejas de los estudiantes y las familias: la de la extraordinaria extensión

\footnotetext{
${ }^{47}$ Exposición dirigida al Excmo. Sr. Ministro de Fomento, de 20 de octubre de 1894, en VILLALAÍN BENITO, J.L., Manuales Escolares en España. Tomo I. Legislación sobre libros de texto (1812-1939), Madrid, Universidad Nacional de Educación a Distancia, 1997, pp. 229-233. Esta publicación forma parte de los resultados del ambicioso proyecto MANES, dirigido por Alejandro Tiana y que ha logrado catalogar y reunir una magnífica colección de manuales escolares de los siglos XIX y XX.

48 Véase, sobre la polémica en las Cortes, en la prensa y el debate, asimismo, entre los propios profesionales de la enseñanza, en el ya mencionado trabajo de CANES GARRIDO, F., "El debate sobre los libros de texto en Secundaria en España", cit., pp. 366-369.

${ }^{49}$ Anuario legislativo de Instrucción Pública, años 1894, 1898 y 1900. La "maraña de normas dictadas en torno al libro de texto en la época de entresiglos" demuestra -a juicio de BENSO CALVO, C. y RIVAS BARROS, I.- que aquellas no se cumplían en la práctica, "sobre todo en lo que a la extensión y comercialización de los libros se refiere", "Los manuales utilizados en los institutos gallegos en la segunda mitad del siglo XIX", cit., p. 201.
} 
de algunos textos, a la que acompañaba su elevado precio y, en la práctica, además la imposibilidad de sustraerse a utilizar el manual recomendado por el profesor.

En 1898, cuando se acomete la reordenación de la segunda enseñanza, la cuestión sigue ocupando al Gobierno:

[...] Elegidas y distribuidas convenientemente las materias de estudio, y señalada la edad en que puede el alumno ser admitido en el Instituto, importa fijar la atención en los instrumentos del trabajo docente para marcar sus condiciones. Es incomprensible -insistirá la exposición de motivos del Real decreto de 13 de septiembre de 189850- la multiplicación, verdaderamente pasmosa, de los libros de texto cuando esa multiplicación no aumenta ni en la más insignificante medida, el caudal de nuestros conocimientos, ni añade en general un átomo al activo de nuestro balance intelectual.

No quiere el Ministro que suscribe coartar en lo más mínimo la libertad del Catedrático para profesar y exponer las doctrinas que sustenta, siempre que se conformen con las prescripciones de la moral y las leyes fundamentales del país; pero no puede tampoco tolerar que se abuse de esa misma libertad para corromper el gusto literario ni para explotar las posiciones oficiales. Lo menos que a un escritor puede exigirse es que sepa escribir con corrección, lo menos que puede reclamarse a un autor didáctico es que se ajuste en la exposición de su doctrina a la verdad científica y enseñe lo que debe enseñar.

La conclusión de lo expuesto no podía ser otra que la necesidad de "poner un freno a la libertad de los textos". En este sentido, el Real decreto de reordenación de la segunda enseñanza dedicaba el Título III a regular los programas y los libros de texto:

Toda asignatura de segunda enseñanza -rezaba el art. 18-, excepto el Dibujo y la Gimnasia, deberán ser expuestas con arreglo al libro de texto adoptado por el Catedrático titular, y el cual se ajustará necesariamente al programa para el examen.

Los programas de cada asignatura, salvo la libertad del Catedrático para formarlos en cuanto al orden y distribución en lecciones de las materias respectivas, deberán ajustarse, en cuanto a su contenido sustancial, a los índices de materias que, a juicio del Consejo de Instrucción Pública, deban comprender.

Cada catedrático podía, lógicamente, elegir el texto que tuviese por conveniente, debiendo, en todo caso, tratarse de un manual que hubiese obtenido el dictamen favorable del Consejo de Instrucción Pública y la correspondiente Real orden de aprobación del libro ${ }^{51}$.

En el comienzo del siglo XX, el recién inaugurado Ministerio de Instrucción Pública y Bellas Artes dispuso la formación por el Consejo de Instrucción Pública de un Cuestionario oficial para exámenes y declaró la no obligatoriedad de adquirir libros de texto ${ }^{52}$. En el

50 Gaceta de Madrid, de 14 de septiembre.

51 Ibídem, Arts. 18-24 del Real decreto de 13 de septiembre de 1898.

52 Real decreto de 6 de julio de 1900, Gaceta de Madrid, de 8 de julio. La exposición del ministro García Alix abundaba en el problema real que enfrentaba las facultades de los profesores para desarrollar libremente su 
Cuestionario quedaban fijados "el fin, carácter y extensión de cada asignatura de las incluidas en el plan de estudios", de suerte que los profesores debían desarrollar sus programas de conformidad con el mismo. Los programas debían a su vez someterse a la consideración de la Junta de profesores del Instituto. Por lo que se refiere a los libros de texto, los señalados por el profesor deberán haber sido aprobados por el Consejo de Instrucción Pública o por la Junta de profesores del Instituto, que tendría asimismo competencias para resolver acerca de su retirada, en su caso, ante una reclamación tocante a la extensión, condiciones didácticas o precio del libro de texto.

Las medidas adoptadas en los años siguientes abundarían en la bondad del Cuestionario y en la no obligatoriedad de la adquisición de los manuales que recomendase los profesores. Se afirmaba así que los alumnos "podrán estudiar por los que mejor estimen, siempre que adquieran los conocimientos que constituyen la asignatura con arreglo al cuestionario oficial" ${ }^{\prime 2}$. La calidad de los textos debería a su vez quedar garantizada con la intervención prevista del Consejo y del propio cuerpo de profesores. En la práctica, sin embargo, el problema persistía y -como señala Canés- los sucesivos Gobiernos debían enfrentar cada año, al comienzo del curso escolar, las quejas de alumnos y padres de familia y también con las reclamaciones de algunos libreros, que querían que los manuales no pudiesen venderse en los propios establecimientos educativos y, como no, a la insatisfacción del profesorado ${ }^{54}$. El debate sobre los libros de texto desembocó a la postre en un debate sobre los propios exámenes, sobre un sistema de enseñanza, esencialmente memorístico, que colocaba en el centro al libro de texto "porque el programa y el examen están sujetos a un libro, y éste tiene que ser, naturalmente, el del Catedrático; no ofrecido, es verdad, por éste, pero sí buscado por el alumno"55. El profesorado, hastiado en parte de las constantes alusiones a prácticas abusivas, no renunciaba, sin embargo, a la elaboración de su propio programa y, si era posible, de su libro de texto.

La reforma de la segunda enseñanza acometida al poco de iniciarse la Dictadura de Primo de Rivera, reconociendo la necesidad de mejorar la calidad de los textos y de resolver un problema enquistado desde hacía varias décadas, resolvió establecer la existencia de libros oficiales y prohibir, al tiempo, la formación y venta de otros materiales didácticos complementarios o alternativos al libro de texto oficial ${ }^{56}$. El texto oficial contaba con la garantía de su aprobación por parte de las correspondientes Comisiones calificadoras ${ }^{57}$,

actividad y la obligación del Estado de procurar la satisfacción del interés general en la esfera de acción que a él, como ministro de Instrucción Pública, le correspondía.

53 Art. 31 de la Ley de 1 de febrero de 1901, disponiendo que el Gobierno, por medio del Consejo de Instrucción Pública, redacte un cuestionario de exámenes, Gaceta de Madrid, del 2 de febrero.

54 CANES GARRIDO, F. “El debate sobre los libros de texto en Secundaria en España”, cit., p. 377.

55 En este sentido Eduardo Vicenti, Política pedagógica, Madrid, 1916, t. I, pp. 549-550, cit. por ibídem.

56 Real decreto de 23 de agosto de 1926, convocando un concurso de libros de texto para los Institutos de Segunda Enseñanza, en VILLALAÍN BENITO, J.L., Legislación sobre libros de texto, cit., pp. 287-292.

57 Del proceso de selección de textos oficiales, puesto en marcha rápidamente por el Gobierno de la Dictadura, de suerte que la constitución de los correspondientes Comisiones Calificadoras tuvo lugar a comienzos del mes de diciembre de 1926, así como el retraso en las previsiones del Gobierno y los resultados de los sucesivos concursos, se ha ocupado CANES GARRIDO, F., "El libro de texto único de segunda enseñanza en la Dictadura de Primo de Rivera”, en Los manuales de texto en la enseñanza secundaria, cit., pp. 41-65. 
pero generó malestar entre el profesorado que vio, además, como la reforma acometida apenas dos meses después -el ya mencionado anteriormente Plan Callejo- modificaba, a peor, sus condiciones laborales. Tampoco fue bien acogido el nuevo sistema de exámenes por grupos de materias afines. La oposición a la reforma se centró en el libro oficial de texto, del que se decía no existía ejemplo conocido en otros países europeos, atentaba contra la libertad de cátedra y estaba llamado a fracasar en la práctica ${ }^{58}$.

En efecto, al no contarse con libros de texto oficiales en todas las asignaturas del plan de estudios de Bachillerato, continuaron publicándose y utilizándose manuales de aquellas materias en las que no había oficiales. Los catedráticos -como ha explicado Canes Garrido-59 hacían constar en sus libros, en algunos casos, que no habían sido presentados al concurso oficial de libros de texto y hacían constar al principio que los contenidos se adaptaban a los cuestionarios oficiales.

Este sería el caso del manual de la asignatura "Rudimentos de Derecho" elaborado por quien era responsable de la docencia en esta materia en estos años. El autor, es en el momento de publicación del manual, profesor de la asignatura "Rudimentos de Derecho" y director del entonces denominado Instituto Nacional de Logroño. Carece, como sus predecesores en la enseñanza de esta asignatura en el centro de la capital riojana, de formación jurídica específica ${ }^{60}$. Es autor, como también otros de aquéllos, de diferentes obras de su especialidad. En 1932 publicó un Compendio de Psicología61. A ésta seguirían, probablemente en los años cuarenta, las tituladas Teoría del conocimiento ${ }^{62}$, Los sistemas filosóficos ${ }^{63}$ y Compendio de Ontología ${ }^{64}$. Todas ellas con una orientación fundamentalmente instructiva, como lo serán también las vinculadas a los programas de las diferentes asignaturas impartidas como catedrático de enseñanza secundaria de Gerona y Logroño publicadas a partir de los años treinta ${ }^{65}$.

58 Las opiniones vertidas por algunos contemporáneos de las reformas, en CANES GARRIDO, F., "El debate sobre los libros de texto en Secundaria en España", cit., pp. 389-391.

59 Ibídem, p. 193.

60 Como antes apunté, se licenció en Filosofía y Letras por la Universidad de Zaragoza. Su expediente académico puede consultarse en Archivo Histórico Nacional, Universidades, leg. 6853, exp. 15.

61 TERÉS GARRIDO, C., Compendio de psicología, Logroño, Imprenta y Librería Moderna, 1932.

62 El ejemplar conservado en la Biblioteca Nacional carece de indicación acerca del editor o la fecha de edición. En la Biblioteca de La Rioja se conserva una quinta edición, fechada en 1950 -cinco años después del fallecimiento del autor-y editada en Logroño por Gráficas Ochoa.

63 TERES GARRIDO, C., Los sistemas filosóficos, Logroño, Gráficas Ochoa, 1954. Se indica, en este caso, que la obra habría sido completa por el doctor en Filosofía, Fernando Montero Moliner, catedrático de Filosofía en el Instituto logroñés desde 1950, hasta su traslado a Barcelona diez años más tarde.

64 Tan solo he localizado un registro en la Biblioteca Nacional de la obra Compendio de Ontología. Se indica que tiene una extensión de 95 páginas y se apunta como fecha probable 1942 y que carece de identificación del editor.

65 Prontuario de Lógica, Logroño, Imprenta Moderna, 1930; Ética Elemental, Logroño, Imprenta Moderna, 1931; Nociones de Ética, Logroño, Imprenta Moderna, s/fha; Nociones de Filosofía: quinto curso de Bachillerato, completada por Fernando Montero Moliner, Logroño, 1954; Nociones de Psicología, Logroño, Imprenta Moderna, 1942; Prontuario de deberes éticos y cívicos conforme al cuestionario oficial, Logroño, Imprenta y Librería Moderna, 1931 
De todas éstas, la que aquí interesa es la titulada Rudimentos de derecho, de la que utilizo el ejemplar conservado en la Biblioteca de La Rioja ${ }^{66}$. Este libro de texto, como otros tantos similares, no contiene ninguna indicación acerca de su fecha de publicación, pero no cabe duda de que se trata de una edición -a la que probablemente habrían precedido otrasrealizada en el último trimestre del año 1932. El dato significativo que permite datarla es la inclusión, a modo de apéndice localizado al final de la obra, de unas cuantas páginas relativas al recién aprobado Estatuto de Cataluña.

El día 15 de septiembre, año 1932, se firmó el Estatuto de Cataluña, después de discutido y sancionado por las Cortes, del que damos una breve síntesis, apunta al comienzo del Apéndice titulado "Estatuto de Cataluña"67.

Se trataría, por tanto, del texto utilizado por los alumnos de sexto curso de Bachillerato del Instituto Nacional de Logroño, en el curso en el que se había extinguido ya el plan de estudios que estaban cursando. El último, por tanto, en el que se impartiría la asignatura "Rudimentos de Derecho".

Este libro de texto -similar a los publicados por otros catedráticos de enseñanza secundaria- debía responder a la finalidad por la que el legislador había decidido, más de treinta años atrás, incluir una formación elemental de Derecho en el currículum de la enseñanza media o secundaria. En el caso del manual de Calixto Terés, no se incluye declaración alguna por parte del autor en relación a los objetivos o fines de la asignatura, que sí es posible encontrar en otros, que incluyen algunas palabras previas a modo de prólogo:

Exposición breve, clara y sencilla: no es otra la finalidad de este trabajo -apunta el autor de un manual publicado poco después en Barcelona-, dedicado a quienes no dispongan para su estudio más que del reducido tiempo de un curso académico ${ }^{68}$.

Dedicada -señalan dos profesores del Instituto zaragozano y abogados del Ilustre Colegio de Zaragoza en una obra se miliares características publicada un cuarto de siglo antes-á los que, deseosos de poseer cultura general y sin poder especializar en el estudio del derecho, aspiren a conocer en sus líneas generales el contenido de las diferentes ramas jurídicas ${ }^{69}$.

Terés no abre su texto con un prólogo. Como tampoco incorpora un índice de las materias abordadas en el manual y que, como después se verá, responden a una organización interna en capítulos y artículos que resulta poco habitual.

66 Rudimentos de Derecho. Conforme al cuestionario oficial, por Calixto Terés Garrido, Catedrático del Instituto Nacional de Logroño, Imprenta y Librería Moderna, Logroño, s/a.

67 Ibídem, p. 147. Sorprende, sin embargo, la referencia -al tratar, en el capítulo III, del Poder legislativo- a la composición del Congreso en el "actual año 1934". La explicación podría estar en que se tratase de una errata, o bien en que se hubiesen llevado a cabo posteriores ediciones del mismo texto sin que conllevase actualización alguna de sus contenidos.

68 FELIÚ EGIDIO, V., Manual de Rudimentos de Derecho, Barcelona, Sola y Ferrer, 1933.

${ }^{69}$ GASCÓN MARÍN, J. y CATALÁN LATORRE, A., Derecho Patrio. Rudimentos de Derecho, Zaragoza, 1908. 
Por lo demás, los Rudimentos de Derecho de Terés responden a un modelo de libro de texto con el que se pretende acercar conceptos complejos a los estudiantes mediante el empleo de los recursos didácticos al alcance del profesor: utiliza un lenguaje sencillo, recurriendo en muchos casos a la etimología de las palabras, o a ejemplos cercanos, para hacer asequibles los conceptos más complejos; organiza los contenidos en apartados muy breves que faciliten el estudio por los estudiantes; prescinde por completo de notas y citas eruditas; huye de la literalidad de los textos legales, cuya transcripción destaca mediante el uso de otra tipografía cuando lo considera imprescindible; finalmente, incorpora al final de los diferentes capítulos del manual una suerte de cuestionario que facilita, de una parte, destacar y repasar los contenidos esenciales y, de otro lado, comprobar si el estudiante ha alcanzado un aprendizaje significativo a partir de la lectura del manual.

Son estas últimas cuestiones, situadas al final de cada lección bajo la rúbrica "Aplicación doctrinal" las que permiten conocer el nivel de conocimientos exigidos a los estudiantes en cada una de las materias y las que pueden sorprender al lector de hoy que tropieza con preguntas como la formulada acerca de si un animal o una mujer son personas, o sobre la edad a la que pueden comenzar a trabajar los niños ${ }^{70}$.

Sin embargo, el autor evita dejar de manifiesto -como sí ocurre en otros tantos manuales de diferentes autores- su pensamiento conservador frente a las novedades introducidas por los casi inmediatos acontecimientos de la vida política española. Con todo, su condición de filósofo, la de sacerdote y su ideología conservadora, está presente en algunos de los ejemplos o preguntas dirigidas a los estudiantes, o, aunque en muy contadas ocasiones, en el propio discurso del texto. Así, en las primeras páginas, al tratar de los derechos innatos y, en particular, a la "libertad de pensamiento", tras exponer su contenido y límites, añade "ni tampoco tenemos libertad para pensamientos malos, por ejemplo, deshonestos, porque los prohíbe y castiga Dios, ya que a ellos no alcanza la sanción de los hombres". En su exposición del Derecho civil, al dar cuenta del matrimonio y su disolución, no duda en aclarar que "la iglesia sólo admite el [divorcio] imperfecto, de tal suerte que, aun separados los esposos, no pueden casarse con otros". 0, al tratar de las causas modificativas de la capacidad jurídica incluye una breve referencia a la reciente Ley que había afectado la correspondiente a las confesiones y Congregaciones religiosas. Dedica además un capítulo completo del manual a la exposición del Derecho canónico, disciplina que no aparece contemplada en otros textos de la misma época al quedar fuera del cuestionario oficial. Tanto este último capítulo en su integridad, como otros pasajes de la obra en que queda de manifiesto el pensamiento propio del autor son "destacados" por él mismo mediante el uso de una tipografía de inferior tamaño.

Por lo que se refiere a la organización de los contenidos, no puede hablarse de la tradicional división en lecciones. El autor se decide -como antes dije-, por una confusa estructura en capítulos y artículos, de suerte que resulta un texto organizado en nueve capítulos y los ya mencionados preliminares y el apéndice. Los denominados "artículos",

70 Resultan ciertamente llamativas las preguntas formulas a los estudiantes al finalizar el apartado dedicado al estudio del concepto de persona y de la capacidad jurídica son las siguientes: “¿Son personas los pájaros?, ¿Y las mujeres?, ¿Es usted persona natural o moral? ...”; o la planteada al tratar de los derechos innatos: ¿Tiene el niño alguna clase de derechos?, ¿El derecho de libertad se extiende a toda clase de obras o palabras?”. 
que aparecen numerados correlativamente dentro de cada capítulo, responden a lo que, en otros libros de texto, se ha señalado como "puntos o preguntados", en los que el autor condensa la explicación sobre un determinado concepto o institución ${ }^{71}$.

Los "preliminares" son destinados -como es habitual en estos libros de texto- a ofrecer al estudiante una primera aproximación al concepto de derecho, de derecho subjetivo, a la relación entre derecho y deber, o las clasificaciones del derecho. No incluye, sin embargo, referencia alguna a las fuentes del derecho en el ordenamiento jurídico español, siendo ésta la cuestión con la que abre el primero de los "artículos" destinados al estudio del derecho civil. Ni tampoco incluye mención alguna a la historia del derecho español, que si había formado del currículo de la asignatura en planes de estudio anteriores

Concluidos los preliminares -como se verá en el siguiente apartado en el que he incluido una suerte de índice de las materias abordadas en el libro de texto-, van desgranándose las sucesivas materias. Comienza por el Derecho civil, al que dedica el capítulo más extenso del manual: un total de catorce "artículos" en los que se sigue, en general, el orden expositivo habitual: concepto de derecho civil, derecho civil común y derechos forales; derecho de la persona; derechos reales; sucesiones; obligaciones y contratos. El segundo de los bloques va destinado al estudio del derecho mercantil, en el que, condensa toda la materia en dos artículos titulados, respectivamente, "De los comerciantes" y "De los contratos mercantiles". Un tercer bloque se refiere al Derecho político. En este la materia se estructura en cuatro partes o artículos, comenzando por la propia definición de derecho político y de Estado, para concluir con el estudio de la Constitución de 1931. El capítulo cuarto, con una extensión de ocho artículos, comienza con la delimitación conceptual del derecho administrativo, aborda, seguidamente, las potestades de la Administración, deteniéndose después en sus diferentes ámbitos de actuación y concluyendo con la referencia a las funciones, medios y régimen económico del Estado. En este bloque se inserta también la denominada "Legislación obrera". Los capítulos quinto y sexto se destinan al Derecho penal y procesal, respectivamente. Se cierra la exposición con sendos capítulos dedicados al Derecho internacional tanto público como privado y con un último capítulo, que comprende tres capítulos, en el que la atención se centra en el Derecho canónico, siendo ésta la principal diferencia que puede observarse en relación a otros manuales de la asignatura publicados en la misma época, que responden a una organización de contenidos muy similar.

Para concluir, es preciso advertir, que, por lo que se refiere a la edición misma, el manual de Calixto Terés Garrido adolece del cuidado que puede observarse en otros textos. Se perciben algunos errores tipográficos sin importancia. Pero también otros que resultan más llamativos, como el hecho de la utilización de forma confusa de diferentes tipos de letra, o el uso de negritas, mayúsculas que no parecen responder, al menos en todos los casos, a la voluntad del autor de resaltar o de llamar, por el contrario, la atención sobre la menor relevancia de un texto, o quizá simplemente de proporcionar al alumno un esquema lógico

71 Por ejemplo, en la obra de Manuel POLO PEYROLON, Rudimentos de derecho, Valladolid, Tipografía Moderna, 1914, analizada por MOLERO PINTADO, A., "La enseñanza de los Rudimentos del Derecho en el Bachillerato de principios del siglo XX. Estudio de casos", en Los manuales de texto en la enseñanza secundaria, cit., p. 345. 
que facilite el aprendizaje de una materia que les resultaba extraña y considerablemente densa. A mi juicio, excepción hecha de aquellas cuestiones incluidas en el libro de texto que no formaban parte del currículo y para las que, intencionadamente, sin duda, el autor utiliza una letra de inferior tamaño, el resto de los casos responde, sin más, al escaso cuidado de la edición.

En el índice que se incluye en el siguiente apartado -no incluido, como antes dije, en el manual- he respetado, en todo caso, el uso de las negritas, cursivas, mayúsculas y de los diferentes tamaños de letra decididos por el autor.

\section{III.3. Apéndice}

\section{PRELIMINARES.}

Título I. Derecho: su noción. - Definición etimológica del Derecho. - Concepto general del mismo. - Doble acepción del Derecho. - Derecho objetivo: su definición. - La Ley moral, fundamento del Derecho. División del Derecho objeto en Natural y positivo y definiciones de éstos. - Subdivisiones del Derecho positivo.

Título II. Del Derecho como facultad. - Definición del Derecho subjetivo y explicación de sus términos. Correlación entre el Derecho subjetivo y el deber jurídico. - Concepto de los Derechos innatos. - Idem de los adquiridos. - Caracteres de los derechos innatos. - Enumeración y explicación de los derechos innatos. - Derivación de los derechos innatos de los derechos negativos.

\section{CAPÍTULO PRIMERO}

Artículo I. Del Derecho positivo. - Definición del Derecho positivo. -Fuentes del mismo. -Definición y explicación de la ley. -Necesidad de la ley. -Condiciones que debe reunir la ley. -La costumbre como fuente del Derecho y su definición. -División de la costumbre. -Requisitos de la costumbre para ser fuente de ley. -Codificación del derecho: su concepto. -Ventajas de la codificación.

Artículo II. Derecho Civil. -Definición del Derecho civil. -Contenido del mismo y tratados en que se divide. -Promulgación del Código civil vigente en España. -Legislaciones forales españolas.

Artículo III. De la persona y su capacidad. -Definición de persona y personalidad. -Clases de personas y sus definiciones. -Concepto de persona jurídica. -Qué entendemos por estado y capacidad de las personas. -Causa determinativa de la personalidad y modificativas de la capacidad jurídica. -Explicación de las mismas. -Cuándo se extingue la personalidad.

Artículo IV. De la familia. -Concepto de la familia y explicación de sus fines. -Elementos formal y material que la integran. -Qué entendemos por parentesco y sus clases. -Idea y enumeración de las líneas y grados de parentesco. -Cómo se cuentan los grados de parentesco en la línea recta y en la colateral, en el derecho canónico y en el civil.

Artículo V. De la Sociedad conyugal. -Definición etimológica de la Sociedad conyugal y concepto de la misma. -Definición del matrimonio. -Formas del matrimonio. -Fines del matrimonio. -Requisitos del matrimonio civil. -Celebración del matrimonio civil.

Artículo VI. De los impedimentos del matrimonio. -Definición de los impedimentos. -División de los impedimentos y breve enumeración de los mismos. -El matrimonio como sacramento: su definición. Propiedades del matrimonio canónico. -Requisitos que preceden y acompañan al matrimonio como contrato y como sacramento. -Impedimentos dirimentes para contraer el matrimonio canónico. Impedimentos canónicos impedientes. -Derechos y deberes de los cónyuges. -Bienes del matrimonio y su distinta consideración. -Concepto del divorcio y su doble acepción. -Causas del divorcio y efectos del mismo.

Artículo VII. De la Sociedad paterno-filial. -Definición de la Sociedad paterno-filial. -Elementos formal y material que lo integran. -Concepto de la patria potestad. -Fundamento de la patria potestad: extensión y extinción de la misma. -Clases de hijos, y sus derechos. -Emancipación de los hijos: edad para obtenerla; derechos que concede, y quién puede concederla. -Definición de sociedad heril. -Elementos integrantes de la sociedad heril y relaciones entre amos y criados. 
Artículo VIII. De la adopción y la tutela. -Definición de la adopción. -Requisitos de la adopción. -Derechos y deberes del adoptante y del adoptado. -Definición de tutela. -Finalidad de la misma. -Clases de tutela y breve explicación de las mismas. -Derecho y deberes del tutor. -Concepto de la protutela, oficios del protutor, y a quién corresponde su nombramiento. -Concepto del Consejo de familia, su composición y competencia. -Registro de tutelas.

Artículo IX. De los derechos reales. -Concepto de los derechos reales. -División de los mismos. -Bienes: sus clases. -Definición de propiedad. -Formas de propiedad. -Del dominio sobre las cosas. -Qué entendemos por posesión. -Clases de posesión y de poseedor. -Cómo se adquiere y pierde la posesión. Concepto de la accesión. -La accesión de los inmuebles y en los muebles.

Artículo X. Limitaciones de la propiedad. -Definición del usufructo. -Cómo se constituye el usufructo y cómo se extingue. -Obligaciones del usufructuario. -Concepto del derecho de uso y habitación. -Carácter de ambos. -Definición de servidumbre. -Clases de servidumbre. -Clases de servidumbre y su constitución. -Registro de la propiedad.

Artículo XI. Modos de adquirir la propiedad. -Cuáles son los modos de adquirir la propiedad. -Qué entendemos por ocupación. -Definición de donación. -Explicación de las donaciones pura, remuneratoria, onerosa, mortis causa e inter vivos. -Validez de las donaciones y anulación de las mismas. -Definición de la prescripción y requisitos de la misma. -Prescripción de los bienes muebles, de los inmuebles y de las acciones.

Artículo XII. De la sucesión. -Qué entendemos por sucesión hereditaria. -Conceptos de herencia, herederos, legatarios, sucesión testamentaria, legítima y mixta. -Definición de testamento y sus caracteres. -Clases de testamentos. -Exposición breve de los mismos. - Quiénes son herederos forzosos y sus legítimas. -Qué son mejoras y legados. -Sucesión intestada: sus casos. -Otras personas y actos de las herencias.

Título [sic.] XIII. De las obligaciones y contratos. -Definición de obligación. -Origen y especies de las obligaciones. -Extinción de las obligaciones. -Definición de contrato. -Requisitos de los contratos.

Artículo XIV. Definición y breve exposición de los contratos onerosos y gratuitos, sobre bienes matrimoniales, de compraventa, permuta, arrendamiento, censual, de sociedad, de mandato, préstamo, comodato, depósito, aleatorios, fianza, prenda, hipotecas y anticresis. -Concepto de cuasicontratos.

\section{CAPÍTULO SEGUNDO. Derecho mercantil}

Artículo I. De los comerciantes. - Definición del Derecho mercantil. -Caracteres del Derecho mercantil. Concepto del comercio. -Clasificación del comercio. -Quiénes son comerciantes. -Capacidad mercantil. Registro mercantil y libros de comercio. -Lugares de contratación mercantil. -Compañías mercantiles. Breve exposición de las colectivas, comanditarias y anónimas. -Agentes mediadores. -Cuentas en participación.

Artículo II. De los contratos mercantiles. -Qué se entiende por contrato mercantil. -Enumeración y exposición de la compraventa, préstamo, transporte terrestre, seguro, fianza y depósito. -Comercio marítimo: sus contratos. -Noción del cambio mercantil. -Enumeración y exposición de la letra de cambio, libranza, vales, pagarés, cheques y cartas órdenes de crédito como instrumentos de cambio. -Suspensión de pagos y quiebras.

\section{CAPÍTULO TERCERO. Derecho político}

Artículo I. Del Estado y sus fines. -Concepto del Derecho político. -Definición de Sociedad y Estado: sus diferencias. -Fines esenciales y accidentes del Estado. -Elementos materiales del Estado y exposición de los mismos.

Artículo II. De los poderes del Estado. -Definición de la soberanía. -Concepto del poder del Estado. Enumeración de los poderes del Estado y sus funciones. -El poder legislativo en España. -Formación del Congreso. Número y prerrogativas de los diputados. -Celebración de las Cortes. -Diputación Permanente. -Referéndum. -Promulgación de las leyes.

Artículo III. Continuación de los poderes del Estado. -Del Poder judicial. -Organización del Poder Ejecutivo. -Poder moderador: su función. -Facultades del Presidente de la República.

Artículo IV. Formas del Estado. -Concepto de Nación y su diferencia del Estado. -Qué entendemos por formas del Estado. -Qué se entiende por forma unitaria del Estado. -Idem por forma compuesta. -Qué es 
unión personal del Estado y qué unión real. -Qué son federaciones de Estados y qué Estados federados. Qué son formas de gobierno. -Enumeración y exposición de las formas de gobierno sociales. -Idem de las formas de gobierno orgánicas.

Artículo V. De la Constitución española. -Definiciones de Constitución y Estado constitucional. -La Constitución vigente en España. -Reforma de la Constitución. -Tribunal de Garantías Constitucionales. Disposiciones originales de la Constitución. -Organización nacional. -Nacionalidad española. -Garantías Constitucionales. -Suspensión de garantías constitucionales.

\section{CAPÍTULO CUARTO. Derecho administrativo}

Artículo I. Del objeto, potestades y esferas del Derecho Administrativo. -Definición del Derecho administrativo. -Qué se entiende por administración. -Objeto, fin y medios de la administración. -Breve enumeración de las potestades administrativas. -Esferas de la administración. -Órganos de la administración pública y jerarquía administrativa. -Centralización y descentralización.

Artículo II. De la Administración Central. -Qué se entiende por Administración Central y quién es el Jefe supremo de la misma. -Qué son los Ministros del Estado: su responsabilidad y atribuciones. -Directores generales y sus funciones. -Ministerios existentes en España. -Asuntos de cada uno de ellos. -Cuerpos consultivos.

Artículo III. De la administración provincial. -Qué entendemos por provincia. -Gobernadores civiles y sus atribuciones. -Qué entendemos por Diputaciones provinciales. -Diputados. -Atribuciones de las diputaciones. -Qué entendemos por Municipio. -Qué son entidades locales menores y cuáles son. -Qué es Ayuntamiento. -Clasificación de los habitantes de un Municipio. -Composición de los Ayuntamientos. Concejales: su número, renovación y exclusiones. -Quienes pueden ser electores. -Alcaldes: su doble función y elección. -Comisión permanente y Junta Municipal. -Recursos contra los acuerdos del Ayuntamiento.

Artículo IV. De las funciones del Estado. -En qué consisten las funciones administrativas. -Clasificación de las mismas. -Policía sanitaria de poblaciones y rural. -Seguridad personal y su policía. -Instrucción pública. -Enseñanza privada. -Enseñanza oficial. -Escuelas nacionales. -Institutos. -Universidades y Escuelas especiales. -Función administrativa respecto a lo moral. -Idem sobre la Beneficencia pública y privada. -Función del Estado sobre el bienestar económico. -Función relativa al orden público. Estadística.

Artículo V. Legislación Obrera. -Intervención del Estado en la cuestión del Trabajo. Razón de la intervención del Estado en esta cuestión. -Creación del Ministerio de Trabajo y sus resultados. -El Código del Trabajo y su contenido. -Contrato del Trabajo. -El aprendizaje. -Los accidentes del Trabajo. -Tribunal Industrial. -Jurados Mixtos Profesionales. -Composición de los Jurados Mixtos. -Atribuciones de los Jurados Mixtos. -Consejo de Trabajo. -Delegaciones provinciales de Trabajo. -Ley de coligaciones y huelgas.

Artículo VI. Del trabajo y sus instituciones. -Jornada legal de trabajo. -El trabajo de mujeres y niños. -Ley del descanso dominical. -Seguro obrero obligatorio. -Seguro de invalidez. -Seguro de maternidad. -Caja Nacional contra el paro forzoso. -Bolsas de Trabajo. -Otras instituciones sociales.

Artículo VII. De los medios del Estado. -Qué son medios del Estado. -Su división en personales y materiales. -Qué es el servicio militar. -Alistamiento e incorporación. -Tiempo y situaciones del servicio militar. -Exclusiones. -Prórroga y sus clases. -De las cuotas: sus clases. -Servicio de marina y su duración. -Medios materiales propios del Estado. -Breve idea de los bienes de dominio público.

Artículo VIII. Del régimen económico. -Qué se entiende por Hacienda pública. -Qué se entiende por ingresos y gastos. -Concepto del presupuesto: su división. -Presupuestos del Estado: su formación. Presupuesto provincial: su formación. -Presupuesto municipal: su formación. -Reclamaciones y tiempo de las mismas.

\section{CAPÍTULO QUINTO. Derecho penal}

Artículo I. -Definición del Derecho penal. -Aspecto jurídico y social de la pena. -Definición del delito y sus caracteres. -Clases de delitos y grados. -Qué entendemos por delincuente. -Concepto del autor, del cómplice y del encubridor de un delito. -Circunstancias que eximen, atenúan o agravan la responsabilidad criminal. 
Artículo II. De la pena. -Definición de la pena. -Necesidad de la pena para restablecer el orden jurídico perturbador [sic.]. -Breve idea de la venganza, represión, convención, defensa social, utilidad, expiación y corrección como finalidades de las penas. -Clasificación de las penas. -Extinción de las penas. Prescripción de delitos y penas. -Condena o remisión condicional. -Libertad condicional. -Clases de delitos contenidos en el Código penal.

\section{CAPÍTULO SEXTO. Derecho procesal}

Artículo I. -Definición de Derecho procesal. -Qué se entiende por jurisdicción y sus clases. -Concepto de la competencia y sus clases. -Definición de juicios. -División de los juicios. -Qué es juicio civil declarativo y sus clases. -Concepto de los juicios de mayor cuantía y sus etapas. -Concepto del juicio de menor cuantía. -Concepto del juicio verbal. -Concepto de los juicios ejecutivos. -Juicios singulares y universales. -Juicio criminal: sus etapas. -Tribunal del Jurado. -Idea de las resoluciones judiciales. -Concepto del recurso y sus clases. -Nociones complementarias.

\section{CAPÍTULO SÉPTIMO. Derecho internacional}

Artículo I. Del Derecho Internacional Público. -Definición del Derecho internacional público. -Fuentes del Derecho internacional. -Sujeto del Derecho internacional. -Clasificación de los Estados. -Derechos y deberes de los Estados. -Vida de relación internacional. -Los tratados y sus clases. -Qué entendemos por Cuerpo diplomático. -Qué son agentes diplomáticos: sus categorías y prerrogativas. - Qué entendemos por agentes consulares y sus clases. -Atribuciones de los mismos. -Conflictos internacionales. -Medios pacíficos de resolverlos. -Medios violentos. -Los tratados de paz. -Sociedad de Naciones.

\section{CAPÍTULO OCTAVO.}

Artículo I. Derecho internacional privado. -Definición del Derecho internacional privado. -Necesidad del mismo y fuentes. -Problemas que plantea y resuelve el Derecho internacional privado sobre la entrada y permanencia en país extranjero y acerca de la capacidad y estado de las personas. -Idem sobre la propiedad de bienes; sucesiones legítimas, testamentos y contratos. -Teorías de la territorialidad, de la personalidad, de la reciprocidad, de los estatutos y de la sumisión. -Legislación española de derecho internacional privado.

\section{CAPÍTULO NOVENO. Derecho canónico}

Artículo I. -Definición del Derecho canónico. -Fuentes del Derecho canónico. -Definición de la Iglesia. Derechos de la Iglesia a gobernar a los fieles, a administrar sus bienes, y a juzgar e imponer penas. -Qué se entiende por Concordatos. -Qué son Concilios y sus clases.

Artículo II. De la jerarquía eclesiástica. -Quiénes son miembros de la Iglesia. -Qué entendemos por jerarquía eclesiástica, sus clases y personas que la integran. -Qué es el Sumo Pontífice, y su institución. Elección del Romano Pontífice. -Qué son Legados Pontificios.

Artículo III. -Delitos eclesiásticos: sus clases. -Penas eclesiásticas. -Breve idea de las censuras, de las penas vindicativas, de los remedios penales y de las penitencias.

\section{APÉNDICE. Estatuto de Cataluña.}

